\title{
Lactic Acid Bacteria Co-Encapsulated with Lactobionic Acid: Probiotic Viability during In Vitro Digestion
}

\author{
Sara Sáez-Orviz $1,+\left(\mathbb{C}\right.$, Francesca Passannanti ${ }^{2,3, *,+}+\mathbb{C}$, Marianna Gallo ${ }^{2,3,4, *} \mathbb{C}$, Rosa Colucci Cante ${ }^{2}$, \\ Federica Nigro ${ }^{3}$, Andrea Luigi Budelli ${ }^{2,5}$, Manuel Rendueles ${ }^{1}\left(\mathbb{D}\right.$, Roberto Nigro ${ }^{2}{ }^{\circledR}$ and Mario Díaz ${ }^{1}$ \\ 1 Department of Chemical and Environmental Engineering, University of Oviedo, C/Julián Clavería 8, \\ 33006 Oviedo, Spain; saezsara@uniovi.es (S.S.-O.); mrenduel@uniovi.es (M.R.); mariodiaz@uniovi.es (M.D.) \\ 2 Department of Chemical, Materials and Production Engineering, University of Naples Federico II, \\ Piazzale Tecchio 80, 80121 Naples, Italy; rosa.coluccicante@unina.it (R.C.C.); \\ Andrea.Budelli@kraftheinz.com (A.L.B.); rnigro@unina.it (R.N.) \\ 3 Innovation \& Technology Provider (ITP S.r.l.), via Bisignano a Chiaia 68, 80121 Naples, Italy; \\ federica.nigro@itpna.it \\ 4 Department of Engineering, University of Rome Niccolò Cusano, Via Don Carlo Gnocchi 3, 00166 Rome, Italy \\ 5 Heinz Innovation Center, Nieuwe Dukenburgseweg 19, 6534 AD Nijmegen Postbus 57, \\ NL-6500 AB Nijmegen, The Netherlands \\ * Correspondence: francesca.passannanti@itpna.it (F.P.); marianna.gallo@unicusano.it (M.G.) \\ + Contributed equally to the work.
}

check for updates

Citation: Sáez-Orviz, S.; Passannanti, F.; Gallo, M.; Colucci Cante, R.; Nigro, F.; Budelli, A.L.; Rendueles, M.; Nigro, R.; Díaz, M. Lactic Acid Bacteria Co-Encapsulated with Lactobionic Acid: Probiotic Viability during In Vitro Digestion. Appl. Sci. 2021, 11, 11404. https://doi.org/ 10.3390/app112311404

Academic Editor: Maria Kanellaki

Received: 15 October 2021

Accepted: 29 November 2021

Published: 2 December 2021

Publisher's Note: MDPI stays neutral with regard to jurisdictional claims in published maps and institutional affiliations.

Copyright: (c) 2021 by the authors. Licensee MDPI, Basel, Switzerland. This article is an open access article distributed under the terms and conditions of the Creative Commons Attribution (CC BY) license (https:// creativecommons.org/licenses/by/ $4.0 /)$
Abstract: Synbiotic products are a type of functional food with great potential due to consumer interest in foods that improve health and/or reduce the risk of certain diseases. In this study, synbiotic macrocapsules were developed using Lactobacillus paracasei CBA L74 as probiotic and lactobionic acid (LBA) as prebiotic. Firstly, the probiotic was proven to be able to use LBA as the only substrate source checking their growth and lactic acid production. Then, four different types of capsules were produced using sodium alginate as matrix and different hardener solutions $\left(\mathrm{CaCl}_{2}\right.$ and chitosan). The macrocapsules were characterised regarding their strength, and the best performing ones were used for further analysis. In order to obtain a synbiotic capsule characterized by a longer stability time due to low water activity, the capsules were dried using freeze and thermal drying. Successively, to revitalize the microorganisms, the capsules were rehydrated in two different media (saline solution and yogurt), subjected to simulated in vitro digestion tests and visually characterised. In addition, their viability over time was assessed. As a result, L. paracasei was able to grow using LBA as the only source of carbon with better production of lactic acid for prolonged periods. The more resistant freeze- and thermal-dried capsules showed differences in rehydration kinetics, and visual changes were also observed. In simulated in vitro digestion tests, capsules rehydrated in yogurt showed the best results in terms of survival. Regarding their viability over time, the importance of the use of chitosan was noted.

Keywords: synbiotic; prebiotic; probiotic; macrocapsules; in vitro digestion; drying processes; lactic acid bacteria; lactobionic acid; Lactobacillus paracasei CBA L74; viability

\section{Introduction}

Currently, consumers desire high quality food products that, apart from fulfilling their nutritional demands, have the potential to improve their health and/or reduce the risk of some diseases [1]. In this context, functional foods have emerged, especially in the area of dairy products, where the greatest variety of functional food products is to be found $[2,3]$. These functional foods contain various bioactive compounds such as prebiotics and probiotics.

The group of prebiotics is broad, and lactose derivatives such as lactobionic acid (LBA) have generated strong interest in the food field [4]. As with other prebiotics, it is resistant to digestive enzymes [5] and can be metabolised by the microflora of the gastrointestinal tract 
(GIT) [6,7]. However, its use has only been approved by the Food and Drug Administration (FDA) in its salt form [8], although it is expected to be approved by other authorities in the near future. Prebiotic compounds have the ability to promote the growth of probiotic microorganisms. Probiotics are live microorganisms that, when administered in appropriate doses, have beneficial effects on consumers [9]. These bacteria have the capacity to withstand the acidic environment of the stomach and reach the lower GIT, where they can convert carbohydrates into lactic acid and other essential nutrients. In addition, they prevent the development and growth of pathogenic microorganisms [9]. The most common and widely used probiotics are lactic acid bacteria (LAB), especially bacteria belonging to the genera Lactobacillus and Bifidobacterium [10]. Specifically, Lactobacillus paracasei CBA L74 has been tested as a probiotic in in vivo studies [11] and has shown various health benefits [11-14].

It has also been successfully used in the development of probiotic non-dairy matrix foods [15-23]. Moreover, when probiotics are combined with prebiotic compounds, synbiotic products are obtained $[24,25]$ and, some authors have suggested that this synbiotic combination may increase the viability of the bacteria through the GIT $[25,26]$.

These bioactive compounds are usually sensitive to chemical and physical factors [27]. To protect them against external agents, different strategies have been explored, such as the development of films, coatings, or encapsulation techniques. Among the matrices that can be used, alginate gels are a suitable matrix to protect and immobilise cells, as they also allow the diffusion of metabolisms through pores [28]. The choice of the coating material and the production conditions of the capsules (hardening times, crosslinking agents, and concentrations) are all factors that can influence the viability of the probiotic and must be carefully investigated [29]. Encapsulation techniques have the capacity to protect probiotic bacteria [10] and also allow other bioactive products to be subjected to different drying techniques, such as heat drying and freeze-drying, which can extend their shelf life [30]. In addition, these types of techniques can increase the survival and viability of probiotics as they pass through the acidic environment of the stomach to reach the GIT.

The ultimate goal of the present work was to develop a dried synbiotic capsule, with LBA as prebiotic and L. paracasei CBA L74 as probiotic, that allows a sufficient quantity of bacteria to be conveyed to the intestine for a functional effect and that has a certain stability over time.

For this purpose, the ability of the probiotic to consume LBA as a single substrate source was first assessed. Then, four synbiotic capsules with different coatings were developed with sodium alginate and characterised in terms of strength. The capsule type with the best characteristics was subjected to two different drying processes (thermal drying and freeze-drying), and the ability to rehydrate in two different media (saline solution and yogurt) was tested in both. The viability over time of the encapsulated probiotic was assessed and, finally, the survival of the L. paracasei was analysed in simulated in vitro digestion tests.

\section{Materials and Methods}

\subsection{Probiotic Microorganism, Growth Conditions and Lactic Acid Production}

Lactobacillus paracasei CBA L74 (patented and provided by Heinz Italia S.p.A) was used as the probiotic microorganism. This strain is a Gram-positive homo-fermentative, and facultative anaerobic bacteria. It was stored at $-20{ }^{\circ} \mathrm{C}$ and revitalized in $10 \mathrm{~mL}$ of animal-free broth (AFB) (20 g/L Bacto Yeast Extract (BD Biosciences, Milan, Italy), $0.5 \mathrm{~g} / \mathrm{L} \mathrm{MgSO}_{4}$ (Sigma-Aldrich, Milan, Italy), $50 \mathrm{~g} / \mathrm{L}$ glucose (Sigma-Aldrich), $0.5 \mathrm{~g} / \mathrm{L}$ citric acid (Sigma-Aldrich)) by incubation at $37^{\circ} \mathrm{C}$ for $24 \mathrm{~h}$. The bacterial load reached after revitalization was approximately $8 \log _{10} \mathrm{CFU} / \mathrm{mL}$.

To test whether L. paracasei is able to use LBA as a substrate source, fermentation tests on three different AFB (different in terms of carbon source) were carried out. Briefly the revitalized strain was centrifuged (1600 rpm for $10 \mathrm{~min}$ ), the supernatant discharged, and the pellet resuspended in $40 \mathrm{~mL}$ of fresh $A F B$ and incubated at $37^{\circ} \mathrm{C}$ for $72 \mathrm{~h}$. To verify the abil- 
ity of the strain to use a carbon source other than glucose, three AFBs were tested: AFB-G, in which the carbon source was glucose; AFB-L in which the source was LBA; and AFB-GL, in which the source was a mix of the two (1:1 ratio) (all were purchased by Sigma-Aldrich). An initial bacterial load of approximately $6 \log _{10} \mathrm{CFU} / \mathrm{mL}$ was observed for all. To monitor fermentation, samples were taken at the start of fermentation (T0) and after 2 (T2), 18 (T18), 24 (T24), 48 (T48), and 72 (T72) h from inoculation. Samples were analysed for microbial growth and lactic acid production. After serial dilutions, samples were sowed on MRS agar (Sigma-Aldrich) plates, then incubated at $37^{\circ} \mathrm{C}$ for $48 \mathrm{~h}$. The lactic acid produced during fermentation was determined by high performance liquid chromatography (HPLC) (Agilent Technologies 1100), equipped with a C18 column (Agilent Zorbax C18 column$4.6 \mathrm{~mm} \times 150 \mathrm{~mm}$ and a pore size of $80 \mathrm{~A}$ ), with visible/UV detector. The eluent was $0.1 \mathrm{M}$ $\mathrm{NH}_{4} \mathrm{H}_{2} \mathrm{PO}_{4}$ aqueous solution at $\mathrm{pH}$ of 2.7 with a flow rate of $0.8 \mathrm{~mL} / \mathrm{min}$; the detection wavelength and temperature were set at $218 \mathrm{~nm}$ and $30^{\circ} \mathrm{C}$, respectively.

\subsection{Co-Encapsulation of the Probiotic and the Prebiotic and Macrocapsule Characterization}

\subsubsection{Encapsulation}

Four different formulations were developed (Table 1). The probiotic was grown under optimal conditions in an animal-free broth with LBA as an exclusive source of carbon (AFB-L). To the microbial culture, $20 \mathrm{~g} / \mathrm{L}$ sodium alginate (Sigma-Aldrich) was added and mixed until a homogeneous solution was obtained. Then, the mixture was dropped into a $\mathrm{CaCl}_{2}$ solution $(0.1$ or $0.5 \mathrm{M}$, Sigma-Aldrich) from a distance of $10 \mathrm{~cm}$ using a $1 \mathrm{~mL}$ sterile syringe. The capsules were left in the $\mathrm{CaCl}_{2}$ solution for a set time (Table 1) at room temperature with gentle agitation. After this time, some of the capsules were collected and added to a chitosan solution (4.42 g/L chitosan (Sigma-Aldrich), $0.44 \%$ glacial acetic acid (Sigma-Aldrich), pH 5.7-6.0 with $\mathrm{NaOH} 1 \mathrm{M}$ ) in which they were kept at room temperature under gentle agitation for $40 \mathrm{~min}$. Finally, the capsules were recovered and stored for further testing.

Table 1. Summary of the different capsules developed.

\begin{tabular}{ccc}
\hline Capsules & $\mathrm{CaCl}_{\mathbf{2}}$ Solution & Chitosan Solution \\
\hline A & $0.1 \mathrm{M}+10 \mathrm{~min}$ & - \\
\hline B & $0.1 \mathrm{M}+30 \mathrm{~min}$ & - \\
\hline C & $0.1 \mathrm{M}+30 \mathrm{~min}$ & $40 \mathrm{~min}$ \\
\hline $\mathrm{D}$ & $0.5 \mathrm{M}+10 \mathrm{~min}$ & $40 \mathrm{~min}$ \\
\hline
\end{tabular}

\subsubsection{Bloom Test}

The textural properties of the capsules were studied employing the bloom test according to the International Standard ISO 9665 [31] using a TA.XTplus Texture Analyzer (Stable Micro Systems, Godalming, UK). The test was conducted at room temperature using a P/ $0.51 / 2^{\prime \prime}$ probe with a test speed of $0.5 \mathrm{~mm} / \mathrm{s}$ and a load cell of $5 \mathrm{~kg}$. Experiments were carried out in triplicate and reported results corresponded to the mean value.

\subsection{Drying Processes}

After production, capsules with the least (A) and the most (D) crosslinked coating were dried by two different technologies: freeze-drying and thermal drying. Freeze-drying was carried out using a lab scale freeze-dryer (Christ Alpha 1-2 LDplus, Martin Christ, Osterode am Harz, Germany). It lasted $24 \mathrm{~h}$, consisting of a main drying phase at a condenser temperature of $-20^{\circ} \mathrm{C}$, a pressure of $1.0 \mathrm{mbar}$ for $12 \mathrm{~h}$, and a final drying phase for the removal of the residual moisture at a temperature of $-56.5^{\circ} \mathrm{C}$ and a pressure of $0.017 \mathrm{mbar}$ for $12 \mathrm{~h}$. Thermal drying was carried out using a dryer (CL252, Trevi, Rimini, Italy), with an air flow of $0.1-0.3 \mathrm{~m} / \mathrm{s}$, controlling the temperature at $37^{\circ} \mathrm{C}$. The drying lasted $12 \mathrm{~h}$. Capsules were evenly distributed on the surface to ensure homogeneous drying. 


\subsection{Viability over Time}

The impact on the viability of the probiotic over time was assessed for three different variables: changing carbon source, crosslinking of the capsules, and the drying process used.

To test the impact of the carbon source and crosslinking, four different capsules were produced: two were made using AFB-G, as described above, with the least (A from Table 1) and the most (D from Table 1) crosslinked coating; and the other two were produced using AFB-L, and also in this case, two crosslinking levels were used.

In Table 2 are summarized the capsule formulations. All were then subjected to freezeor thermal drying. The produced freeze-dried or thermal-dried capsules were stored at $20^{\circ} \mathrm{C}$, and at specific sampling times the microbial viability was tested. Briefly, the capsules were broken in $1 \% w / w$ sodium citrate solution at $\mathrm{pH} 6$, and after serial dilution the sample was seeded on MRS agar as previously described. The sampling times were (in days): day 0 (T0, the day the drying ended), 1, 2, 4, 6, 8, 11, 14, 18, 21, and 30.

Table 2. Capsule formulations used to test probiotic viability over time, to study the impact from the carbon source used and from the crosslinking of the coating.

\begin{tabular}{ccc}
\hline Capsules & Carbon Source & Coating \\
\hline I & AFB-G & $0.1 \mathrm{M} 10$ min (A from Table 1) \\
\hline II & AFB-G & $0.5 \mathrm{M} 10 \mathrm{~min}+$ chitosan (D from Table 1) \\
\hline III & AFB-L & $0.1 \mathrm{M} 10 \mathrm{~min}$ (A from Table 1) \\
\hline IV & AFB-L & $0.5 \mathrm{M} \mathrm{10} \mathrm{min} \mathrm{+} \mathrm{chitosan} \mathrm{(D} \mathrm{from} \mathrm{Table} \mathrm{1)}$ \\
\hline
\end{tabular}

\subsection{Rehydration Kinetics}

The capsule with the best results in the bloom test and with the higher viability over time was chosen for subsequent experiments. The chosen capsule, both in freeze-dried and thermal-dried forms, was tested for its ability to rehydrate. In particular, two conditions were tested: (1) rehydration in $0.9 \% \mathrm{NaCl}$ solution at $37{ }^{\circ} \mathrm{C}$; (2) rehydration in natural yogurt (Danone, Danone Group SA, France) at $4{ }^{\circ} \mathrm{C}$. Briefly, the capsules (freeze- or thermaldried) were placed in $0.9 \% \mathrm{NaCl}$ solution or in yogurt and collected at specific times $(0,0.25 \mathrm{~min}(15 \mathrm{~s}), 6 \mathrm{~min}, 60 \mathrm{~min}, 180 \mathrm{~min}$ and $1440 \mathrm{~min}(24 \mathrm{~h}))$. Their water content was measured using a volumetric titrator (Karl Fisher HI 903, Hanna instruments, Villafranca Padovana, Italy). Finally, the rehydration capacity of the capsules was evaluated as the ratio between the water content measured in the dried capsules compared to the initial water content of the fresh capsules, as described below:

$$
\left(\mathrm{W}_{\text {rehydrate }} / \mathrm{W}_{\text {fresh }}\right) \times 100
$$

where $\mathrm{W}_{\text {rehydrate }}$ were the grams of water adsorbed by the dried capsule during the rehydration in $0.9 \% \mathrm{NaCl}$ solution or in yogurt, and $\mathrm{W}_{\text {fresh }}$ were the grams of water measured in the fresh capsules before drying.

\subsection{Simulated In Vitro Digestion of Rehydrated Freeze-Dried and Thermal-Dried Capsules}

The in vitro digestion test was performed only with the aim to test the survival of L. paracasei, since LBA is resistant to human digestive enzymes [5]. For this purpose, the viability of the microorganisms was tested at several times during the digestion trial and calculated per gram of capsule. In addition, a sample of free bacteria, unencapsulated, was tested also as control, with an initial concentration of $7 \log _{10} \mathrm{CFU} / \mathrm{mL}$.

The three digestive conditions (salivary, gastric, and intestinal phases) were prepared according to Passannanti et al. [32] with some modifications. Simulated salivary fluid (SSF) was prepared by adding $1.12 \mathrm{~g} / \mathrm{L} \mathrm{KCl}, 0.50 \mathrm{~g} / \mathrm{L} \mathrm{KH}_{2} \mathrm{PO}_{4}, 1.14 \mathrm{~g} / \mathrm{L} \mathrm{NaHCO}, 0.031 \mathrm{~g} / \mathrm{L}$ $\mathrm{MgCl}_{2}\left(\mathrm{H}_{2} \mathrm{O}\right)_{6}$, and $0.0058 \mathrm{~g} / \mathrm{L}\left(\mathrm{NH}_{4}\right)_{2} \mathrm{CO}_{3}$. Simulated gastric fluid (SGF) was prepared by mixing $0.51 \mathrm{~g} / \mathrm{L} \mathrm{KCl}, 0.12 \mathrm{~g} / \mathrm{L} \mathrm{KH}_{2} \mathrm{PO}_{4}, 2.10 \mathrm{~g} / \mathrm{L} \mathrm{NaHCO}_{3}, 2.76 \mathrm{~g} / \mathrm{L} \mathrm{NaCl}, 0.020 \mathrm{~g} / \mathrm{L}$ 
$\mathrm{MgCl}_{2}\left(\mathrm{H}_{2} \mathrm{O}\right)_{6}$, and $0.048 \mathrm{~g} / \mathrm{L}\left(\mathrm{NH}_{4}\right)_{2} \mathrm{CO}_{3}$. Simulated intestinal fluid (SIF) was prepared by adding $0.51 \mathrm{~g} / \mathrm{L} \mathrm{KCl}, 0.11 \mathrm{~g} / \mathrm{L} \mathrm{KH}_{2} \mathrm{PO}_{4}, 7.14 \mathrm{~g} / \mathrm{L} \mathrm{NaHCO}_{3}, 2.24 \mathrm{~g} / \mathrm{L} \mathrm{NaCl}$, and $0.067 \mathrm{~g} / \mathrm{L}$ $\mathrm{MgCl}_{2}\left(\mathrm{H}_{2} \mathrm{O}\right)_{6}$ (all reagents from Sigma-Aldrich).

Before the in vitro digestion test, the thermal-dried and freeze-dried capsules were rehydrated in two different ways: in a saline solution $\left(0.9 \% \mathrm{NaCl}, 1: 100(w / v)\right.$ at $37^{\circ} \mathrm{C}$ for $15 \mathrm{~min}$ ) and in $120 \mathrm{~g}$ of natural yogurt (Danone, Danone Group SA, France) (at $4{ }^{\circ} \mathrm{C}$ for $24 \mathrm{~h}$ ).

For the salivary simulation, $25 \mathrm{~mL}$ of SSF were mixed with $\mathrm{CaCl}_{2}$ (Sigma-Aldrich) and $\alpha$-amylase (1333 U/mg protein, CAS 900-90-2, Sigma-Aldrich) to obtain a concentration in the final volume of $0.083 \mathrm{~g} / \mathrm{L}$ and $75 \mathrm{U} / \mathrm{mL}$, respectively. Capsules rehydrated in saline solution were recovered and added directly while those rehydrated in yogurt were added with $5 \mathrm{~g}$ of yogurt. The oral mixture was incubated for $3 \mathrm{~min}$ at $37^{\circ} \mathrm{C}$. Afterwards, $25 \mathrm{~mL}$ of SGF were added to the mixture. Porcine pepsin (2500 U/mg protein, CAS 9001-75-6, Sigma-Aldrich) and $\mathrm{CaCl}_{2}$ were also added to this mixture to achieve a final concentration of $2000 \mathrm{U} / \mathrm{mL}$ and $0.0083 \mathrm{~g} / \mathrm{L}$. Then, the mixture was well homogenized, the $\mathrm{pH}$ was adjusted to 2.0 with $\mathrm{HCl} 5 \mathrm{M}$ (Sigma-Aldrich) and incubated at $37^{\circ} \mathrm{C}$ for $2 \mathrm{~h}$. Finally, porcine pancreatin $(0.1 \%(w / v)$, CAS $9049-47-6$, Sigma-Aldrich), bovine chymotrypsin (3\% (w/v), CAS 9004-07-3, Sigma-Aldrich), amyloglucosidase (260 U/mL, CAS 9032-08-0), with a concentration in the final volume of $1.12 \mathrm{U} / \mathrm{mL}$, [33]), and $\mathrm{CaCl}_{2}(0.033 \mathrm{~g} / \mathrm{L})$ were mixed with $50 \mathrm{~mL}$ of SIF. This solution was added to the previous mixture and was well homogenized, the $\mathrm{pH}$ adjusted to 6.5 with $\mathrm{NaOH} 5 \mathrm{M}$ (Sigma-Aldrich), and incubated at $37^{\circ} \mathrm{C}$ for $2 \mathrm{~h}$.

The bacterial viability was assessed by taking samples at different times: one after the simulated salivary phase and one after each $30 \mathrm{~min}$ in the simulated gastric and intestinal phases (9 samples in total for the entire simulated digestion trial). For the sampling, a number of capsules were collected and weighed under sterile conditions. The capsules were homogenized and dissolved with a sterile sodium citrate solution $(1 \%(w / w)$, $\mathrm{pH}$ 6.0, Sigma-Aldrich) in a 1:10 proportion (capsule weight/sodium citrate volume). Serial dilutions (1:10) were incubated on MRS agar plates (Sigma-Aldrich) for 48-72 h at $37^{\circ} \mathrm{C}$. Each sample was prepared in triplicate, and results were expressed in $\log _{10} \mathrm{CFU} / \mathrm{g}$ capsules (CFU/mL in the case of control).

\subsection{Visual Characterization and Sphericity Factor (SF)}

The visual characterization of the capsules was performed employing a LEICA M205Fa fluorescence stereo microscope (Leica Microsystems Inc., Heidelberg, Germany). A magnification $12 \times$ was used, and Leica Application Suite v4.0 software platform was used to analyse the images and determine the size of the capsules.

The shape of the capsules was characterised using the spherification factor (SF). According to this parameter, a 0 value is a perfect sphere, and a 1 value corresponds to an elongated sphere. The SF parameter was calculated as follows:

$$
\mathrm{SF}=\left(\mathrm{d}_{\max }-\mathrm{d}_{\min }\right) /\left(\mathrm{d}_{\max }+\mathrm{d}_{\min }\right)
$$

where $d_{\max }$ is the largest diameter and $d_{\min }$ is the smallest diameter perpendicular to $d_{\max }$. SF of the capsules was calculated on fresh capsules, on dried capsules, on rehydrated capsules (saline solution and yogurt), and after the in vitro digestion tests.

\subsection{Statistical Analysis}

Analysis of variance (ANOVA) was applied. Fischer's least significant difference (LSD) was performed to determine significant differences between the data. A level of $p<0.05$ was considered significant. Analyses were carried out using Statgraphics $18^{\circledR}$ Centurion statistical software. 


\section{Results and Discussion}

3.1. Analysis of the Growth of L. paracasei Using Lactobionic Acid as Substrate and Lactic Acid Production

L. paracasei CBA L74 was inoculated in three animal free broths (AFBs) to study its ability to use carbon sources other than glucose. In Figure 1, the bacterial growth (A) and the lactic acid produced (B) during the fermentation are shown.

A

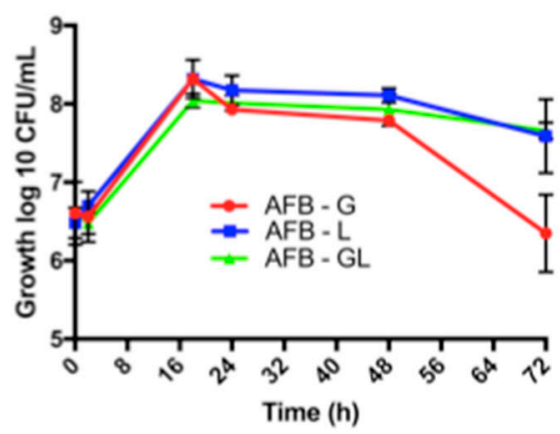

B

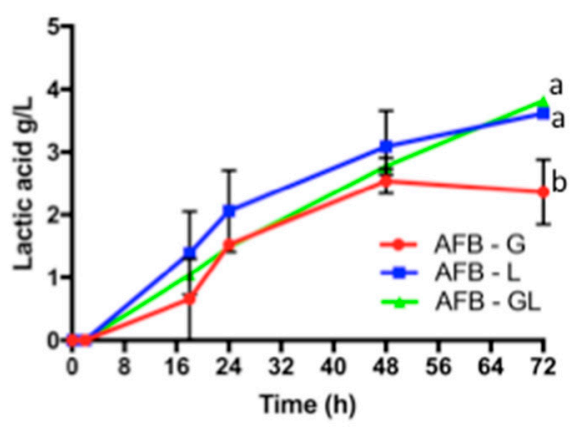

Figure 1. Microbial growth and lactic acid concentrations on three AFBs. (A) Bacterial growth in $\log _{10} \mathrm{CFU} / \mathrm{mL}$ and (B) lactic acid production in $\mathrm{g} / \mathrm{L}$, during fermentation on three different AFBs: AFB-G, with glucose as carbon source; AFB-L, with LBA as carbon source; AFB-GL, with a mix (1:1 ratio) of glucose and LBA. Bars represent standard deviation of three independent experiments. Different letters indicate significant differences $(p<0.05)$.

Starting for all with a bacterial concentration of about $6.5 \log _{10} \mathrm{CFU} / \mathrm{mL}$, similar growth was obtained for all the broths. Only after $72 \mathrm{~h}$ did it seem that the growth of the microorganism in the AFB-G had a reduction in its viability $\left(6.35 \pm 0.49 \log _{10} \mathrm{CFU} / \mathrm{mL}\right)$, but the difference compared with the other broths (AFB-L: $7.59 \pm 0.47 \log _{10} \mathrm{CFU} / \mathrm{mL}$; AFB-GL: $7.66 \pm 0.10 \log _{10} \mathrm{CFU} / \mathrm{mL}$ ) was not statistically significant. As for the lactic acid, it increased over time with a very similar trend for all the broths. Only after $72 \mathrm{~h}$ was a statistically significant difference $(p<0.05)$ observed between the fermentations carried out in the broths with LBA (AFB-L: $3.62 \pm 0.05 \mathrm{~g}$ lactic acid/L; AFB-GL: $3.82 \pm 0.09 \mathrm{~g}$ lactic acid/L) and the fermentation in AFB-G $(2.37 \pm 0.52 \mathrm{~g}$ lactic acid/L). From these results, it was possible to state that $L$. paracasei CBA L74 was able to use LBA as a carbon source, and this substrate gave the same results as glucose in terms of bacterial growth and lactic acid production (with improved production observed over prolonged times). A similar test [6] was performed on different Lactobacillus strains; also, from their study, L. paracasei appeared to be able to grow using LBA $(2 \% w / v)$ in the same way as using glucose.

\subsection{Capsule Characterization}

After having tested the ability of the microorganism to use LBA as a substrate, $L$. paracasei and the prebiotic were co-encapsulated in four different types of capsules, the resistance of which was tested by the bloom test. The strength of the four types of capsules produced was analysed to choose the type of capsule with the best characteristics for further studies. In this type of test, bloom gel strength is the mass in grams required to depress the surface gel $4 \mathrm{~mm}$ [34]. Results are shown in Table 3. The most resistant capsules were those that were made with the highest concentration of $\mathrm{CaCl}_{2}(0.5 \mathrm{M})$ and had an extra layer of chitosan (D-capsules). With the rest of the capsules developed, the employed $\mathrm{CaCl}_{2}$ concentration $(0.1 \mathrm{M})$ did not seem to harden them enough, as even with a chitosan layer (C-capsules), no significant differences were observed $(p>0.05)$. Therefore, the $\mathrm{CaCl}_{2}$ concentration had an influence on the strength of the capsules. Other authors have found that the strength of the sodium alginate gel increases with the $\mathrm{CaCl}_{2}$ concentration, as the formation of stronger and more crosslinked bound gels is favoured due to the presence of more available $\mathrm{Ca}^{2+}$ ions $[35,36]$. Besides that, the chitosan coating provided extra coverage 
in the capsules, which may influence the ability of their structure to make them increase probiotic viability [28] and to withstand the digestive conditions and help the probiotic to survive and reach the lower gastrointestinal tract (GIT). Therefore, D-capsules were chosen for the rest of the analysis performed.

Table 3. Bloom values (g) for the different capsules. Different letters in the same column indicate significant differences $(p<0.05)$.

\begin{tabular}{ccccc}
\hline Capsules & A & B & C & D \\
\hline Force $(\mathrm{g})$ & $253.7 \pm 7.4^{\mathrm{a}}$ & $283.2 \pm 68.3^{\mathrm{a}}$ & $304.3 \pm 52.0^{\mathrm{a}}$ & $476.9 \pm 38.7^{\mathrm{b}}$ \\
\hline
\end{tabular}

\subsection{Viability over Time of the Probiotic Encapsulated in Dried Capsules}

The viability of the microorganism is a key factor in ensuring the probiotic effect on the health of the host. Actually, there is no standard recommendation on the bacterial concentration to consume to have a benefit; however, it is generally accepted that the microorganism, to be defined as a probiotic, must have a concentration of at least $10^{6} \mathrm{CFU}$ per $g$ of product [37]. This bacterial concentration must be guaranteed at the time of consumption and, considering that during storage the vital count can decrease, an assessment of the viability over time is essential. We evaluated the impact on viability over time of: (1) the carbon source used as substrate by the microorganism (testing two different broths: AFB-G and AFB-L; (2) the coating (testing the least $\left(0.1 \mathrm{M} \mathrm{CaCl}_{2}\right.$ for $\left.10 \mathrm{~min}\right)$ and the most ( $0.5 \mathrm{M} \mathrm{CaCl}_{2}$ for $10 \mathrm{~min}$ and chitosan) crosslinked capsules); (3) the drying technology used (freeze- or thermal-dried, considering that for both, a water content of about $0.1 \%$ on dry basis was measured immediately after drying, while a value of less than $2 \%$ was measured after 30 days). In Figure 2, the microbial concentration observed over time (days) is shown. It may be noted that there were no differences due to the carbon source used: the same trend was obtained on capsules with the same structure but revitalized in different broths, and this could be affirmed for both the freeze- and thermal-dried capsules. On the contrary, the resistance of the structure of the capsules seemed to be very important to guarantee stability: the capsules crosslinked in $0.1 \mathrm{M} \mathrm{CaCl}_{2}$ for $10 \mathrm{~min}$ protected the microorganism less than the other types of capsules, with a decay in the microbial concentration of about $4 \log _{10}$ at the end of the time considered. The same reduction was indeed not present if the capsules were produced by crosslinking in $0.5 \mathrm{M} \mathrm{CaCl}_{2}$ for $10 \mathrm{~min}$ and then coated with chitosan. Additionally, in this case the trend between the freeze- and thermal-dried capsules was very similar and no statistically significant differences were found. Furthermore, in the study by Mahmoud et al. [38], the structure of the capsule seemed to be an important factor in determining the probiotic viability over time: it was found that chitosan-coated alginate capsules were more capable than others (with skim milk, dextrin, or denatured whey protein) in protecting L. plantarum during storage. The importance of chitosan coating for probiotic viability during storage was also shown by Lopes et al. [39]. Based on these data, only the microorganisms encapsulated in the most crosslinked capsules, then coated with chitosan, had a useful microbial concentration to be considered probiotics after 30 days of storage, while for the other capsules only half the storage time should be considered. 
A

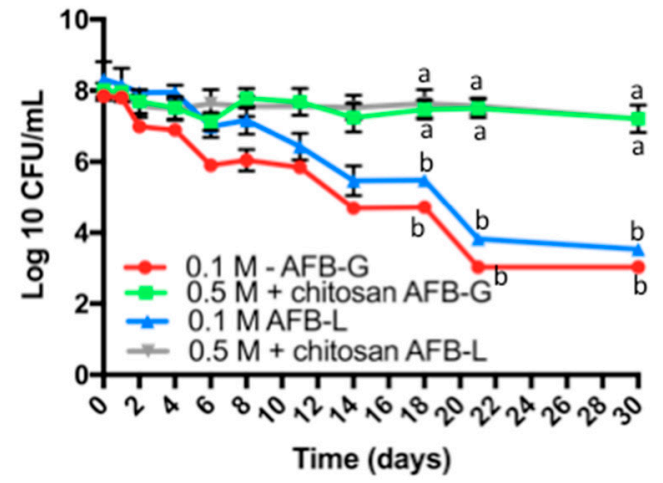

B

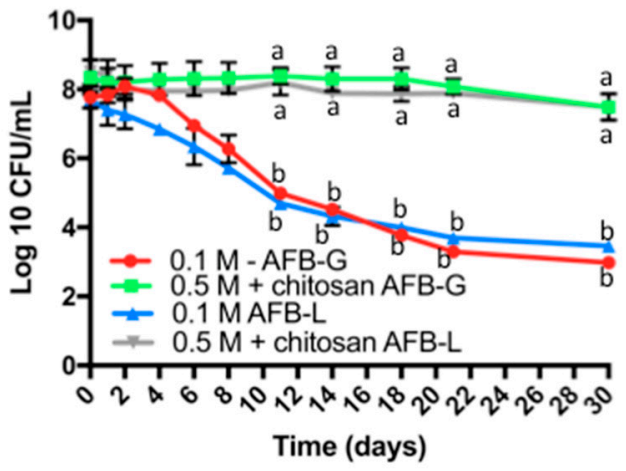

Figure 2. Probiotic viability over time. Microbial concentration measured for 30 days for the freeze-dried capsules (A) and for the thermal-dried capsules (B). For both cases, two parameters were studied: the broth used (AFB-G or AFB-L) and the capsule structure (if crosslinked in $0.1 \mathrm{M}$ $\mathrm{CaCl}_{2}$ for $10 \mathrm{~min}$ or in $0.5 \mathrm{M} \mathrm{CaCl}_{2}$ for $10 \mathrm{~min}$ and then coated with chitosan). Bars represent standard deviation of three independent experiments. Different letters indicate significant differences $(p<0.05)$.

\subsection{Rehydration Kinetics}

Capsules produced with AFB-L, chosen as the best from the bloom test and from the evaluation of viability over time (D-capsules: $0.5 \mathrm{M} \mathrm{CaCl}_{2}$ and chitosan), were then freezeor thermal-dried. The rehydration capacity over time of the capsules was evaluated as the ratio between the grams of water adsorbed by the dried capsules (freeze- or thermal-dried) compared to the grams of water measured in the fresh capsule, before drying, as described in the methods section. The results for rehydration capacity are shown in Figure 3.

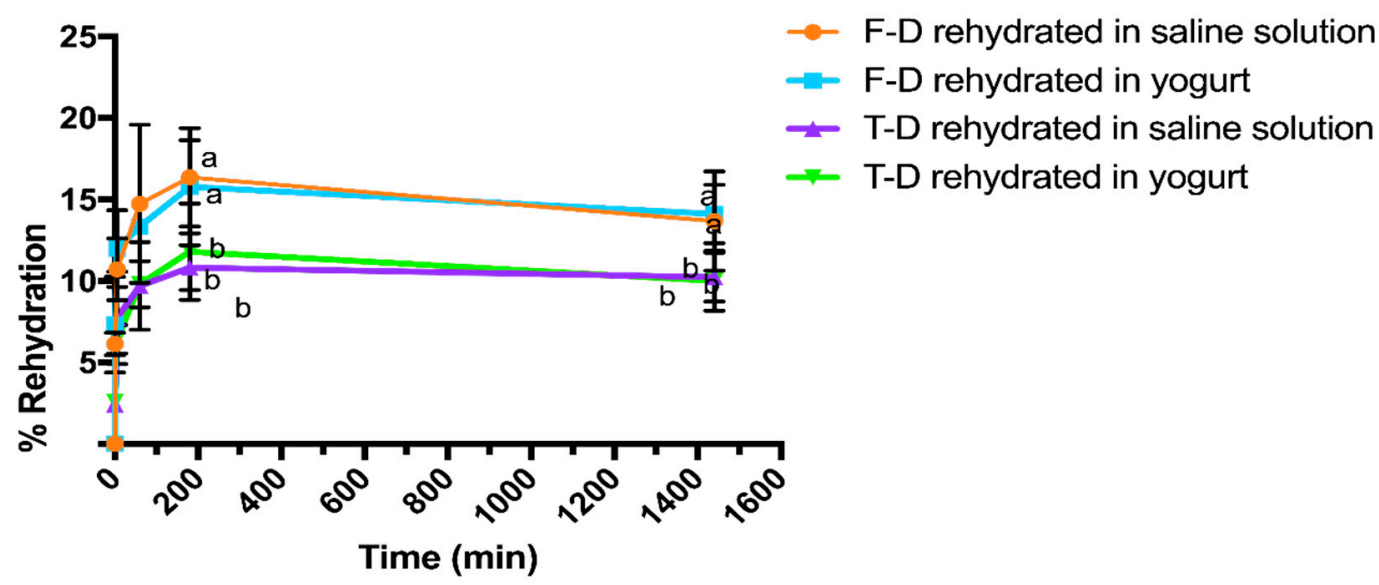

Figure 3. Rehydration capacity over time. Freeze- and thermal-dried capsules were placed in $0.9 \% \mathrm{NaCl}$ solution (orange, purple, respectively) or in yogurt (light blue, green, respectively) and collected at specific sampling times ( $0,0.25 \mathrm{~min}$ (15 s), $6 \mathrm{~min}, 60 \mathrm{~min}, 180 \mathrm{~min}$, and $1440 \mathrm{~min}(24 \mathrm{~h})$ ) to evaluate their rehydration capacity, as described in the methods section. Bars represent standard deviation of three independent experiments. Different letters indicate significant differences $(p<0.05)$.

The freeze-dried capsules were more capable of rehydration than the thermal-dried ones, and the difference was statistically significant. Conversely, there was no difference according to the medium used for rehydration (saline solution or yogurt). In all cases, the rehydration reached a maximum level after $3 \mathrm{~h}$ and lasted until $24 \mathrm{~h}$, when the rehydration percentages observed were $13.67 \pm 3.10 \%$ for the freeze-dried capsules rehydrated in saline solution; $14.12 \pm 1.80 \%$ for the freeze-dried capsules rehydrated in yogurt; $10.24 \pm 1.50 \%$ for the thermal-dried capsules rehydrated in saline solution, and $10.00 \pm 1.84 \%$ for the thermal-dried capsules rehydrated in yogurt. 
The differences related to the drying treatment used could be due to the physical alterations (shrinkage, altered porosity and microstructure, and reduced ability in binding water) caused by thermal drying [40-42].

\subsection{Simulated In Vitro Digestion of Rehydrated Freeze-Dried and Thermal-Dried Capsules}

To evaluate the capacity of the alginate capsules to protect $L$. paracasei survival, freezedried and thermal-dried capsules rehydrated in saline solution and yogurt were subjected to a simulated in vitro digestion test. As a control, unencapsulated L. paracasei $\left(7 \log _{10} \mathrm{CFU} / \mathrm{mL}\right)$ was used. Results are shown in Figure 4.

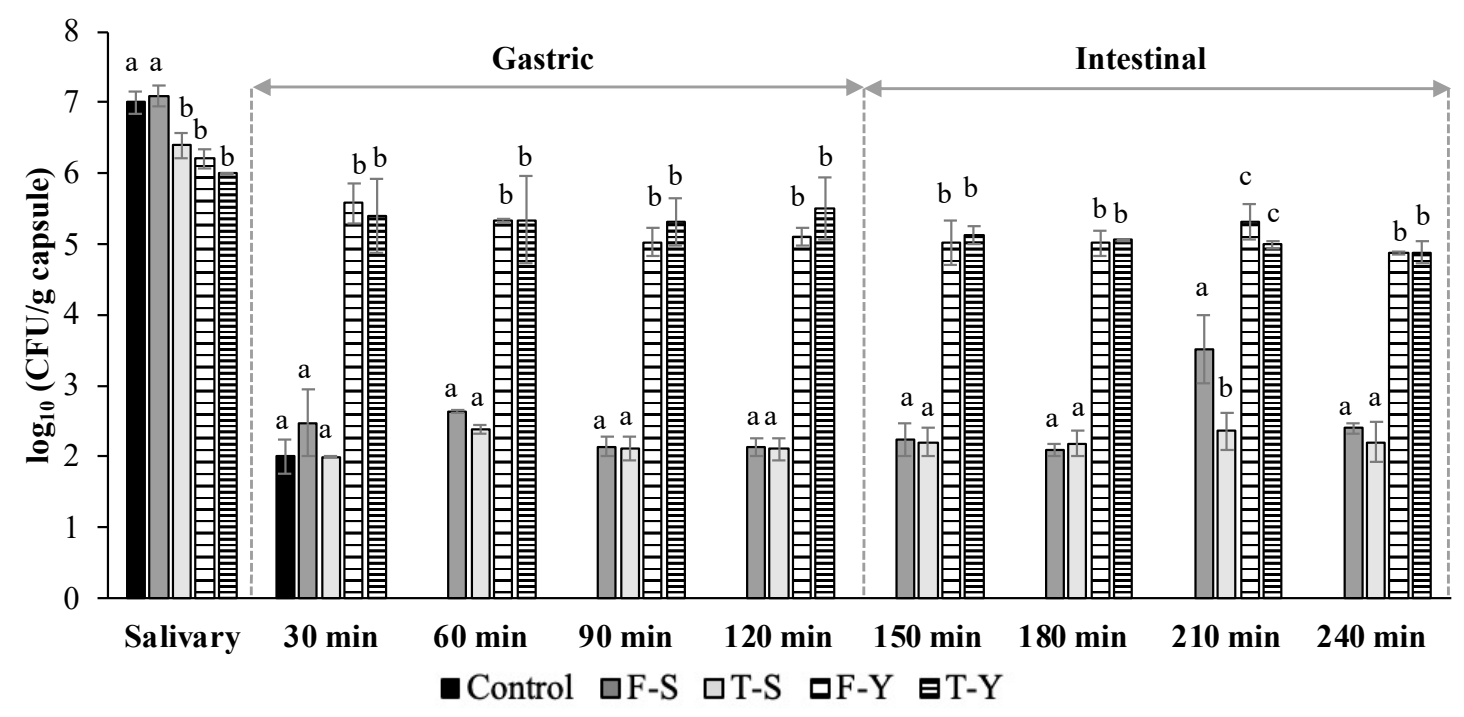

Figure 4. Variation of the concentration of L. paracasei $\left(\log _{10} \mathrm{CFU} / \mathrm{g}\right.$ of capsule and $\log _{10} \mathrm{CFU} / \mathrm{mL}$ in the case of control sample) throughout the in vitro digestion test. F-S refers to freeze-dried capsules rehydrated in saline solution, T-S to thermal-dried capsules rehydrated in saline solution, F-Y to freeze-dried capsules rehydrated in yogurt, and T-Y to thermaldried capsules rehydrated in yogurt. Experiments were carried out in triplicate and reported results correspond to the mean value. Different letters indicate significant differences $(p<0.05)$.

In the simulated salivary phase, the probiotic concentration was equal to or greater than $6 \log _{10} \mathrm{CFU} / \mathrm{g}$ capsules or $\mathrm{mL}$ (in the case of control). The differences observed may be due to the initial concentration of microorganisms in each type of rehydrated capsule and not to the effect of salts and $\alpha$-amylase present in the environment, as the differences were not related to the type of capsule (freeze- or thermal-dried) or the type of hydration (saline solution or yogurt). The main changes were observed in gastric simulation. After $30 \mathrm{~min}$ in the stomach simulation, no survival was observed in the case of the control. It is known that the acidic environment $(\mathrm{pH}<2.0)$ as well as the presence of pepsin can cause the death of the microorganisms [43]. Significant differences $(p<0.05)$ were found in terms of the way the capsules were rehydrated but not between freeze- or thermal-dried capsules. Higher survival was obtained in capsules rehydrated in yogurt than in those rehydrated in saline solution, with a difference of $57.75 \%$. After the simulated gastric phase, there was a small reduction in the microbial load in the simulated intestinal phase. At the final point, the mean survival of capsules rehydrated in saline solution was $2.3 \pm 0.1 \log _{10} \mathrm{CFU} / \mathrm{g}$ capsules, while for those rehydrated in yogurt, it was $4.8 \pm 0.1 \log _{10}$ $\mathrm{CFU} / \mathrm{g}$ capsules. Therefore, the way in which the capsules were rehydrated influenced the survival of the probiotic throughout the simulated in vitro digestion test in both types of capsules (freeze-dried and thermal-dried). Yogurt, with its rich nutritional composition, could play a dual role in the protection of microorganisms: first, by acting as a more complex matrix to digest, compared to saline solution, with more "engaged" digestive enzymes (the same results were obtained by Bove et al. (2013) [44], where different food carriers of probiotics were tested during in vitro digestion, and higher survival was 
observed in complex and/or nutrient-rich ones) and second, by feeding microorganisms with nutrients: during rehydration in yogurt, capsules can absorb water enriched with nourishing molecules such as sugars, which can promote viability.

For probiotic microorganisms to be effective, they must withstand the conditions of the digestive tract to reach the GIT. Although there is no scientific consensus on the probiotic concentration needed to obtain a beneficial effect, several authors suggest that this concentration would be between 6 and $9 \log _{10}$ CFU/day [10,45]. Regarding LBA, it was not measured during the simulated in vitro digestion test, as it is resistant to human digestive enzymes (non-digestible fibre), and it is capable of reaching the large intestine intact [5,46]. In the case of yogurt, the recommended daily intake is between 200 and $250 \mathrm{~g}$ [47], meaning two portions per day (120 g/portion). Considering the results obtained in the simulated in vitro digestion test and adding an amount between 0.75 and $1 \mathrm{~g}$ of capsules per portion of yogurt, capsules rehydrated in saline solution would have a probiotic final mean value between 3.3 and $4.4 \log _{10} \mathrm{CFU} /$ day while capsules rehydrated in yogurt would have a mean value between 7.32 and $9.76 \log _{10} \mathrm{CFU} /$ day. As can be seen from these results, only capsules rehydrated in yogurt would have the capacity to deliver an adequate probiotic dose (a minimum concentration of $6 \log _{10}$ CFU / day) to the lower GIT.

\subsection{Visual Characterization and Sphericity Factor (SF)}

Stereo microscope images of the capsules (fresh, dried, rehydrated, and digested) are shown in Table 4, together with the SF and the weight of the related capsule. In terms of size, freshly made capsules showed a practically spherical shape (SF < 0.05, [48]). After the drying process, the capsules altered their shape. Even so, the SF values obtained ( 0.135 and 0.17 for the freeze-dried and thermal-dried capsules, respectively) were close to the value of a sphere. Significantly, the freeze-dried capsules were more rounded, while the thermal-dried ones were flatter $(0.135 \pm 0.023$ and $0.17 \pm 0.082$, respectively) due to the drying process carried out. This difference was also observed visually (B-1 and C-1).

Table 4. Sphericity factor values (SF), stereo microscope images (all with a magnification of $12 \times$ ) and weight (mg) of the capsules. D (microscope images A) refers to freshly made capsules, F-D (microscope images B1-5) to freeze-dried capsules, and T-D ((microscope images C1-5) to thermal-dried capsules. Different letters indicate significant differences $(p<0.05)$.

\begin{tabular}{ccccc}
\hline Capsules & SF & Microscope Images \\
\hline D & $0.041 \pm 0.021^{\mathrm{a}}$ & Weight (mg) \\
\hline
\end{tabular}

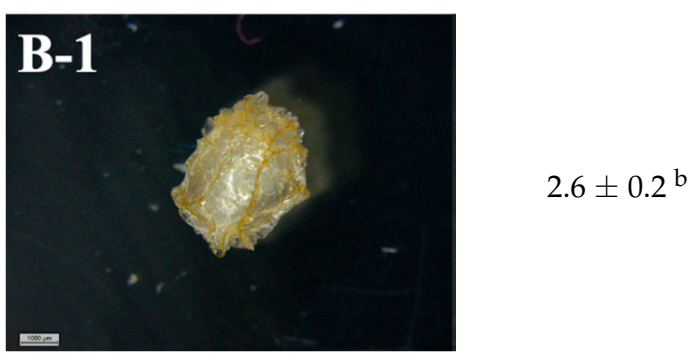

F-D $\quad 0.135 \pm 0.023^{b}$ 
Table 4. Cont.

\begin{tabular}{ccccc}
\hline Capsules & SF & Microscope Images \\
\hline F-D rehydrated in saline solution & $0.049 \pm 0.03^{\mathrm{a}}$ & Weight (mg) \\
\hline $\begin{array}{c}\text { F-D rehydrated in saline solution after } \\
\text { in vitro digestion }\end{array}$ & $0.045 \pm 0.01^{\mathrm{c}}$ \\
\hline
\end{tabular}

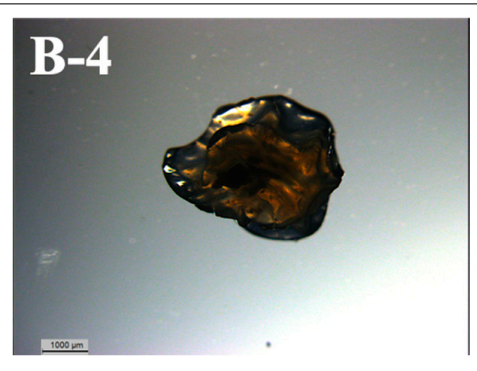

$10.8 \pm 1.3^{\mathrm{e}}$

F-D rehydrated in yogurt

$0.113 \pm 0.04^{b}$

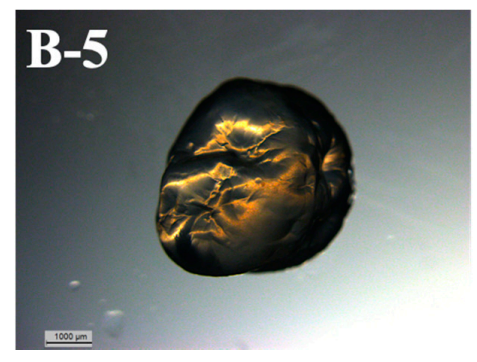

$13.1 \pm 1.1^{\mathrm{d}}$ in vitro digestion

$0.043 \pm 0.023^{a}$

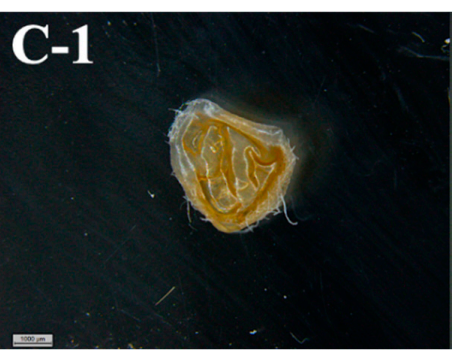

$2.3 \pm 0.4^{b}$

T-D

$0.17 \pm 0.082^{\mathrm{d}}$

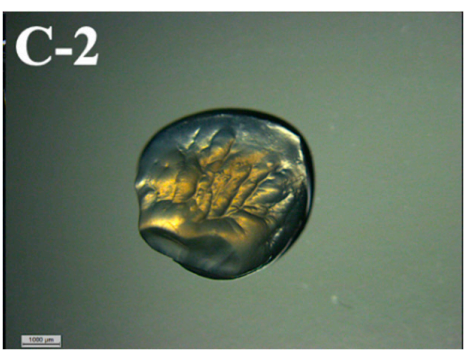

$7.3 \pm 0.4^{\mathrm{f}}$ 
Table 4. Cont.

\begin{tabular}{cccc}
\hline Capsules & SF & Microscope Images & Weight (mg) \\
\hline $\begin{array}{l}\text { T-D rehydrated in saline solution after } \\
\text { in vitro digestion }\end{array}$ & $0.069 \pm 0.045^{\mathrm{e}}$ & & \\
& & \\
\hline
\end{tabular}

T-D rehydrated in yogurt $0.022 \pm 0.013^{\mathrm{f}}$

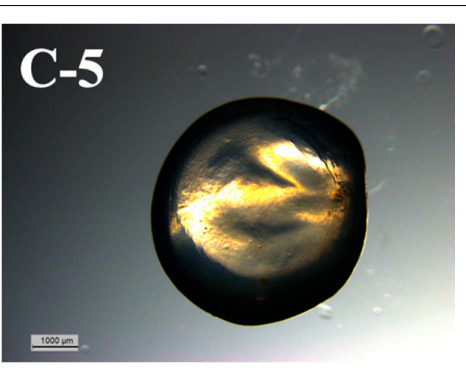

$10.6 \pm 1.3^{\mathrm{e}}$

After the rehydration process, significant differences were found between the weight of the capsules. Freeze-dried capsules showed a higher weight, both after hydration with saline and yogurt and after in vitro digestion tests. These results agreed with those obtained in the rehydration kinetics evaluation (Section 3.4), as the freeze-dried capsules obtained a higher percentage of rehydration and therefore weighed more. In addition, differences in the capsule surfaces after the in vitro simulated digestion tests were observed. The freeze-dried capsules showed a surface roughness (B-3 and B-5) while the thermaldried capsules showed a smooth and uniform surface (C-3 and C-5). In addition, the size of the capsules increased (as shown in B-5 and C-5) (1000 $\mu \mathrm{m}$ scale). Other authors have also found that after simulated in vitro digestion tests, the size of sodium alginate capsules increased throughout the digestion process, up to three times the original size [49].

\section{Conclusions}

As with other studied probiotic bacteria, L. paracasei CBA L74 was able to use LBA as the only source of carbon, showing better results in lactic acid production over prolonged periods of time. Thus, synbiotic macrocapsules with L. paracasei CBA L74 as probiotic and LBA as prebiotic were developed and characterised. The most resistant capsules were those prepared using $0.5 \mathrm{M} \mathrm{CaCl}_{2}$ as hardener and with an extra layer of chitosan. The same capsules protected the microorganisms over time better than the others tested and were chosen for subsequent tests. From rehydration tests, it emerged that regardless of the medium used (saline solution or yogurt), the freeze-dried capsules incorporated water more easily than the thermal-dried ones, but in all cases the rehydration was partial. No differences were observed between the freeze- or thermal-drying processes in terms 
of probiotic viability; hence, the composition of the capsules allowed the survival of the probiotic to be maintained. The way in which capsules were rehydrated was a determining factor in the survival of the probiotic in the simulated in vitro digestion tests: capsules rehydrated in saline solution showed worse viability results compared to capsules rehydrated in yogurt, which could better protect microorganisms thanks to its rich nutritional composition. The synbiotic capsules produced (both freeze-dried and thermal-dried) with the recommended daily intake of yogurt would reach the minimum concentration for the product to be considered "probiotic".

Author Contributions: M.G., F.P. and R.N. designed the research; S.S.-O., F.P., R.C.C. and F.N. performed the experiments; S.S.-O., F.P. and M.G. collected and analysed the data and contributed to the interpretation of the results; A.L.B. provided the raw materials and Lactobacillus paracasei CBA L74; S.S.-O., F.P. and M.G. wrote the paper and had the primary responsibility for the final content. M.R., R.N. and M.D. the original draft. All authors have read and agreed to the published version of the manuscript.

Funding: This work was financially supported by the Spanish Ministry of Science and Innovation through the project MCIU-19-RTI2018-094218-B-100 and by the grant Programa Severo Ochoa de Ayudas Predoctorales para la Investigación y Docencia (grant number BP19-127 to Sáez-Orviz, S.).

Institutional Review Board Statement: Not applicable.

Informed Consent Statement: Not applicable.

Conflicts of Interest: Andrea Budelli is currently employed by Heinz BV, The Netherlands. He provided Lactobacillus paracasei CBA L74. He did not have any additional role in the data collection and analysis, decision to publish, or preparation of the manuscript. Heinz BV did not provide any financial support to the authors for the experimental activity, and did not have any additional role in the study design, data collection and analysis, decision to publish, or preparation of the manuscript.

\section{References}

1. Batista, A.; Silva, R.; Cappato, L.; Ferreira, M.; Nascimento, K.; Schmiele, M.; Esmerino, E.; Balthazar, C.F.; Silva, H.; Moraes, J.; et al. Developing a synbiotic fermented milk using probiotic bacteria and organic green banana flour. J. Funct. Foods 2017, 38, 242-250. [CrossRef]

2. Ashwell, M. Concepts of Functional Foods. Nutr. Food Sci. 2004, 34, 47. [CrossRef]

3. Sáez-Orviz, S.; Puertas, C.; Marcet, I.; Rendueles, M.; Díaz, M. Bioactive synbiotic coatings with lactobionic acid and Lactobacillus plantarum CECT 9567 in the production and characterization of a new functional dairy product. J. Funct. Foods 2020, 75, 104263. [CrossRef]

4. Alonso, S.; Rendueles, M.; Díaz, M. Bio-production of lactobionic acid: Current status, applications and future prospects. Biotechnol. Adv. 2013, 31, 1275-1291. [CrossRef]

5. Cardoso, T.; Marques, C.; Dagostin, J.L.A.; Masson, M.L. Lactobionic Acid as a Potential Food Ingredient: Recent Studies and Applications. J. Food Sci. 2019, 84, 1672-1681. [CrossRef]

6. Saarela, M.; Hallamaa, K.; Mattila-Sandholm, T.; Mättö, J. The effect of lactose derivatives lactulose, lactitol and lactobionic acid on the functional and technological properties of potentially probiotic Lactobacillus strains. Int. Dairy J. 2003, 13, 291-302. [CrossRef]

7. Schaafsma, G. Lactose and lactose derivatives as bioactive ingredients in human nutrition. Int. Dairy J. 2008, 18, 458-465. [CrossRef]

8. FDA. Code of Federal Regulations, Title 21, 21 CFR 172.720; US Food and Drug Administration: Silver Spring, MD, USA, 2017.

9. Peng, M.; Tabashsum, Z.; Anderson, M.; Truong, A.; Houser, A.K.; Padilla, J.; Akmel, A.; Bhatti, J.; Rahaman, S.O.; Biswas, D. Effectiveness of probiotics, prebiotics, and prebiotic-like components in common functional foods. Compr. Rev. Food Sci. Food Saf. 2020, 19, 1908-1933. [CrossRef] [PubMed]

10. Espitia, P.J.; Batista, R.A.; Azeredo, H.M.; Otoni, C.G. Probiotics and their potential applications in active edible films and coatings. Food Res. Int. 2016, 90, 42-52. [CrossRef]

11. Nocerino, R.; Paparo, L.; Terrin, G.; Pezzella, V.; Amoroso, A.; Cosenza, L.; Cecere, G.; De Marco, G.; Micillo, M.; Albano, F.; et al. Cow's milk and rice fermented with Lactobacillus paracasei CBA L74 prevent infectious diseases in children: A randomized controlled trial. Clin. Nutr. 2017, 36, 118-125. [CrossRef]

12. Gallo, M.; Nigro, F.; Passannanti, F.; Nanayakkara, M.; Lania, G.; Parisi, F.; Salameh, D.; Budelli, A.; Barone, M.V.; Nigro, R. Effect of $\mathrm{pH}$ control during rice fermentation in preventing a gliadin P31-43 entrance in epithelial cells. Int. J. Food Sci. Nutr. 2019, 70, 950-958. [CrossRef] [PubMed] 
13. Labruna, G.; Nanayakkara, M.; Pagliuca, C.; Nunziato, M.; Iaffaldano, L.; D’Argenio, V.; Colicchio, R.; Budelli, A.; Nigro, R.; Salvatore, P.; et al. Celiac disease-associated Neisseria flavescens decreases mitochondrial respiration in CaCo-2 epithelial cells: Impact of Lactobacillus paracasei CBA L74 on bacterial-induced cellular imbalance. Cell. Microbiol. 2019, 21, e13035. [CrossRef] [PubMed]

14. Sarno, M.; Lania, G.; Cuomo, M.; Nigro, F.; Passannanti, F.; Budelli, A.; Fasano, F.; Troncone, R.; Auricchio, S.; Barone, M.V.; et al. Lactobacillus paracaseiCBA L74 interferes with gliadin peptides entrance in Caco-2 cells. Int. J. Food Sci. Nutr. 2014, 65, 953-959. [CrossRef]

15. Salameh, D.; Nigro, F.; Cante, R.C.; Passannanti, F.; Gallo, M.; Budelli, A.; Marzocchella, A.; Nigro, R. Fermentation of rice flour supernatant using lactobacillus paracasei CBA L74. Chem. Eng. Trans. 2019, 75, 289-294.

16. Gallo, M.; Nigro, F.; Passannanti, F.; Salameh, D.; Schiattarella, P.; Budelli, A.; Nigro, R. Lactic fermentation of cereal flour: Feasibility tests on rice, oat and wheat. Appl. Food Biotechnol. 2019, 6, 165-172.

17. Cante, R.C.; Gallo, M.; Nigro, F.; Passannanti, F.; Salameh, D.; Budelli, A.; Nigro, R. Lactic fermentation of cooked navy beans by Lactobacillus paracasei CBA L74 aimed at a potential production of functional legume-based foods. Can. J. Chem. Eng. 2020, 98, 1955-1961. [CrossRef]

18. Gallo, M.; Nigro, F.; Passannanti, F.; Salameh, D.; Budelli, A.; Marzocchella, A.; Nigro, R. Rice Fermentation by Lactobacillus Paracasei CBA L74. Int. J. Rice Res. 2018, 2018, 1-5.

19. Gallo, M.; Passannanti, F.; Colucci Cante, R.; Nigro, F.; Salameh, D.; Schiattarella, P.; Schioppa, C.; Budelli, A.; Nigro, R. Effects of the Glucose Addition during Lactic Fermentation of Rice, Oat and Wheat Flours. Appl. Food Biotechnol. 2020, 7, 21-30.

20. Gallo, M.; Passannanti, F.; Cante, R.C.; Nigro, F.; Schiattarella, P.; Zappulla, S.; Budelli, A.; Nigro, R. Lactic fermentation of cereals aqueous mixture of oat and rice flours with and without glucose addition. Heliyon 2020, 6, e04920. [CrossRef]

21. Gallo, M.; Passannanti, F.; Schioppa, C.; Montella, S.; Cante, R.C.; Nigro, F.; Budelli, A.; Nigro, R. Enzymatic pretreatment and lactic fermentation of wheat flour suspension at a high solid content. J. Food Process. Preserv. 2021, 45, e15299. [CrossRef]

22. Gallo, M.; Passannanti, F.; Schiattarella, P.; Esposito, A.; Colucci Cante, R.; Nigro, F.; Budelli, A.; Nigro, R. Banana Puree Lactic Fermentation: The Role of Ripeness, Heat Treatment, and Ascorbic Acid. Appl. Sci. 2021, 11, 5153. [CrossRef]

23. Colucci Cante, R.; Gallo, M.; Nigro, F.; Passannanti, F.; Budelli, A.; Nigro, R. Mathematical Modeling of Lactobacillus paracasei CBA L74 Growth during Rice Flour Fermentation Performed with and without pH Control. Appl. Sci. 2021, 11, 2921. [CrossRef]

24. Langa, S.; Bulck, E.V.D.; Peirotén, A.; Gaya, P.; Schols, H.; Arqués, J. Application of lactobacilli and prebiotic oligosaccharides for the development of a synbiotic semi-hard cheese. LWT 2019, 114, 108361. [CrossRef]

25. Sáez-Orviz, S.; Marcet, I.; Rendueles, M.; Díaz, M. Bioactive packaging based on delipidated egg yolk protein edible films with lactobionic acid and Lactobacillus plantarum CECT 9567: Characterization and use as coating in a food model. Food Hydrocoll. 2021, 119, 106849. [CrossRef]

26. Khalf, M.; Dabour, N.; Kheadr, E.; Fliss, I. Viability of probiotic bacteria in maple sap products under storage and gastrointestinal conditions. Bioresour. Technol. 2010, 101, 7966-7972. [CrossRef] [PubMed]

27. Dias, M.I.; Ferreira, I.C.F.R.; Barreiro, M.F. Microencapsulation of bioactives for food applications. Food Funct. 2015, 6, 1035-1052. [CrossRef] [PubMed]

28. Simó, G.; Fernández-Fernández, E.; Vila-Crespo, J.; Ruipérez, V.; Rodríguez-Nogales, J.M. Research progress in coating techniques of alginate gel polymer for cell encapsulation. Carbohydr. Polym. 2017, 170, 1-14. [CrossRef] [PubMed]

29. Di Natale, C.; Lagreca, E.; Panzetta, V.; Gallo, M.; Passannanti, F.; Vitale, M.; Fusco, S.; Vecchione, R.; Nigro, R.; Netti, P. Morphological and Rheological Guided Design for the Microencapsulation Process of Lactobacillus paracasei CBA L74 in Calcium Alginate Microspheres. Front. Bioeng. Biotechnol. 2021, 9, 660691. [CrossRef]

30. Kaushik, V.; Roos, Y.H. Limonene encapsulation in freeze-drying of gum Arabic-sucrose-gelatin systems. LWT-Food Sci. Technol. 2007, 40, 1381-1391. [CrossRef]

31. International Standard Organization ISO 9665. Adhesives-Animal Glues-Methods of Sampling and Testing; ISO: Geneva, Switzerland, 1998; Volume 1998.

32. Huson, D.; Beier, S.; Flade, I.; G'orska, A.; El-Hadidi, M.; Mitra, S.; Ruscheweyh, H.-J.; Tappu, R. MEGAN Community Edition-Interactive exploration and analysis of large-scale microbiome sequencing data. PLoS Comput. Biol. 2016, 12, e1004957. [CrossRef] [PubMed]

33. Warren, F.; Zhang, B.; Waltzer, G.; Gidley, M.J.; Dhital, S. The interplay of $\alpha$-amylase and amyloglucosidase activities on the digestion of starch in in vitro enzymic systems. Carbohydr. Polym. 2015, 117, 192-200. [CrossRef]

34. García, C.; Ranieri, G.; Rendueles, M.; Díaz, M. Exploring encapsulation strategies as a protective mechanism to avoid amensalism in mixed populations of Pseudomonas taetrolens and Lactobacillus casei. Bioprocess Biosyst. Eng. 2019, 43, 55-66. [CrossRef] [PubMed]

35. Atencio, S.; Maestro, A.; Santamaría, E.; Gutiérrez, J.M.; González, C. Encapsulation of ginger oil in alginate-based shell materials. Food Biosci. 2020, 37, 100714. [CrossRef]

36. Li, L.; Chen, Y.; Wang, Y.; Shi, F.; Nie, Y.; Liu, T.; Song, K. Effects of concentration variation on the physical properties of alginate-based substrates and cell behavior in culture. Int. J. Biol. Macromol. 2019, 128, 184-195. [CrossRef] [PubMed]

37. FAO/WHO. Codex Standard for Fermented Milks, 2nd ed.; n Codex Stan., Ed.; Food Agric. Organ. United Nations: Rome, Italy, 2010; pp. 1-5. 
38. Mahmoud, M.; Abdallah, N.A.; El-Shafei, K.; Tawfik, N.F.; El-Sayed, H.S. Survivability of alginate-microencapsulated Lactobacillus plantarum during storage, simulated food processing and gastrointestinal conditions. Heliyon 2020, 6, e03541. [CrossRef] [PubMed]

39. Lopes, L.A.A.; Carvalho, R.D.S.F.; Magalhães, N.S.S.; Madruga, M.S.; Athayde, A.J.A.A.; Portela, I.A. Microencapsulation of Lactobacillus acidophilus La-05 and incorporation in vegan milks: Physicochemical characteristics and survival during storage, exposure to stress conditions, and simulated gastrointestinal digestion. Food Res. Int. 2020, 135, 109295. [CrossRef] [PubMed]

40. Chirife, J.; Buera, M.P. A critical review of some nonequilibrium situations and glass transitions on water activity values of foods in the microbiological growth range. J. Food Eng. 1995, 25, 531-552. [CrossRef]

41. Stapelfeldt, H.; Nielsen, B.R.; Skibsted, L.H. Effect of heat treatment, water activity and storage temperature on the oxidative stability of whole milk powder. Int. Dairy J. 1997, 7, 331-339. [CrossRef]

42. Witrowa-Rajchert, D.; Lewicki, P.P. Rehydration properties of dried plant tissues. Int. J. Food Sci. Technol. 2006, 41, 1040-1046. [CrossRef]

43. Melchior, S.; Marino, M.; Innocente, N.; Calligaris, S.; Nicoli, M.C. Effect of different biopolymer-based structured systems on the survival of probiotic strains during storage and in vitro digestion. J. Sci. Food Agric. 2020, 100, 3902-3909. [CrossRef]

44. Bove, P.; Russo, P.; Capozzi, V.; Gallone, A.; Spano, G.; Fiocco, D. Lactobacillus plantarum passage through an oro-gastro-intestinal tract simulator: Carrier matrix effect and transcriptional analysis of genes associated to stress and probiosis. Microbiol. Res. 2013, 168, 351-359. [CrossRef] [PubMed]

45. Saad, N.; Delattre, C.; Urdaci, M.; Schmitter, J.M.; Bressollier, P. An overview of the last advances in probiotic and prebiotic field. LWT-Food Sci. Technol. 2013, 50, 1-16. [CrossRef]

46. Sáez-Orviz, S.; Camilleri, P.; Marcet, I.; Rendueles, M.; Díaz, M. Microencapsulation of Calcium Lactobionate for Protection from Microorganisms in a Solid Phase Food. Biochem. Eng. J. 2019, 150, 107281. [CrossRef]

47. Bonjour, J.-P.; Benoit, V.; Payen, F.; Kraenzlin, M. Consumption of Yogurts Fortified in Vitamin D and Calcium Reduces Serum Parathyroid Hormone and Markers of Bone Resorption: A Double-Blind Randomized Controlled Trial in Institutionalized Elderly Women. J. Clin. Endocrinol. Metab. 2013, 98, 2915-2921. [CrossRef] [PubMed]

48. Córdoba, A.L.; Deladino, L.; Martino, M. Effect of starch filler on calcium-alginate hydrogels loaded with yerba mate antioxidants. Carbohydr. Polym. 2013, 95, 315-323. [CrossRef]

49. Gorbunova, N.; Evteev, A.; Evdokimov, I.; Bannikova, A. Kinetics of ascorbic acid transport from alginate beads during in vitro digestion. J. Food Nutr. Res. 2016, 55, 148-158. 